Stubenrauch, Mike; Fischer, Robert; Creutzburg, Heide; Teichman, Caecilie, von; Groß, Gregor Alexander ; Witte, Hartmut:

\title{
Segmented flow microfluidics in multilumen tubing
}

Zuerst erschienen in: $\quad$ Biomedical Engineering = Biomedizinische Technik. - Berlin [u.a.] : de Gruyter. - 57 (2012), Suppl. 1, Track-E, p. 926.

Erstveröffentlichung: $\quad$ 2012-08-30

ISSN (online): $\quad$ 1862-278X

ISSN (print): $\quad$ 0013-5585

DOI: $\quad 10.1515 /$ bmt-2012-4360

[Zuletzt gesehen: 2019-08-12]

„Im Rahmen der hochschulweiten Open-Access-Strategie für die Zweitveröffentlichung identifiziert durch die Universitätsbibliothek IImenau. “

"Within the academic Open Access Strategy identified for deposition by Ilmenau University Library."

„Dieser Beitrag ist mit Zustimmung des Rechteinhabers aufgrund einer (DFGgeförderten) Allianz- bzw. Nationallizenz frei zugänglich."

"This publication is with permission of the rights owner freely accessible due to an Alliance licence and a national licence (funded by the DFG, German

Research Foundation) respectively." 


\section{Segmented flow microfluidics in multilumen tubing}

Mike Stubenrauch, Robert Fischer, Heide Creutzburg, Caecilie von Teichman, Alexander Gross, Hartmut Witte Ilmenau University of Technology, Institute of Micro- and Nanotechnologies MacroNano ${ }^{\circledR}$, Gustav-Kirchhoff-Straße 7, 98693 Ilmenau, Germany

e-mail: hartmut.witte@tu-ilmenau.de

\section{Introduction}

The ongoing miniaturization in microfluidics and segmented flow is currently limited, mainly by the use of commercial standard fluidic connectors and tubing. Multilumen tubing offers a huge potential of minimizing the space consumption for a fluidic port on microchips. However, the direct coupling of such tubes to chips or standard tubing is still a barrier for easy implementation into lab routines.

\section{Methods}

Microfluidic chips for interfacing multilumen tubing are produced by state of the art silicon micromachining processes (lithography, dry etching, bonding etc.). A special dry etching process generates nanostructured surface areas at desired locations, where the tubes are subsequently mounted by a hot molding process. The fluidic paths on the chip allow a wide range of mixing procedures and injection port geometries for optimized segment formation in the external tubing.

\section{Results}

Good quality of segmented flows in multilumen tubing could be shown. Four pumps have been used to generate different segemented flows in two lumina of a 4-lumen tube (a pump for the carrier flow and a pump for the segment flow for each lumen). No cross talk between the fluids of different segments in each lumen and no cross influence of the flow from one channel to the other were observed. However, the reproducibility from chip to chip has to be improved as there is still a lack in alignment precision between the microchip and its fluidic ports and the lumina of the tube.

\section{Conclusion}

The combination of miniaturized microfluidics in multilumen tubing with segmented flow experiments will enhance the functionality of biomedical and biochemical setups in the future. It is possible to have several segmented flows in parallel in the same hardware tube, for storage of segments, for encoding of segments or real time reference experiments. The stable generation of multiple segmented flows in one tube could be demonstrated by using a directly coupled silicon microchip. 